\title{
Amperometric L-glutamate biosensor based on bacterial cell-surface displayed glutamate dehydrogenase
}

\author{
Bo Liang ${ }^{\mathrm{a}, \mathrm{b}, 1}$, Shu Zhang ${ }^{\mathrm{a}, \mathrm{c}, 1}$, Qiaolin Lang ${ }^{\mathrm{a}, 1}$, Jianxia Song ${ }^{\mathrm{c}}$, Lihui Han ${ }^{\mathrm{c}}$, Aihua Liu ${ }^{\mathrm{a}, \mathrm{b}, *}$ \\ a Laboratory for Biosensing, Key Laboratory of Biofuels, and Shandong Provinicial Key Laboratory of Energy Genetics, Qingdao Institute of Bioenergy E \\ Bioprocess Technology, Chinese Academy of Sciences, 189 Songling Road, Qingdao 266101, China \\ ${ }^{\mathrm{b}}$ University of Chinese Academy of Sciences, 19A Yuquan Road, Beijing 100049, China \\ ${ }^{\mathrm{c}}$ Key Laboratory of Marine Chemistry Theory and Technology of Ministry of Education, Ocean University of China, 238 Songling Road, Qingdao 266100, China
}

\section{H I G H L I G H T S}

- E. coli surface-dispalyed Gldh exhibiting excellent enzyme activity and stability.

- Sensitive amperometric biosensor for glutamate using Gldh-bacteria and MWNTs.

- The glutamate biosensor exhibited high specificity and stability.

\section{G R A P H I C A L A B S T R A C T}
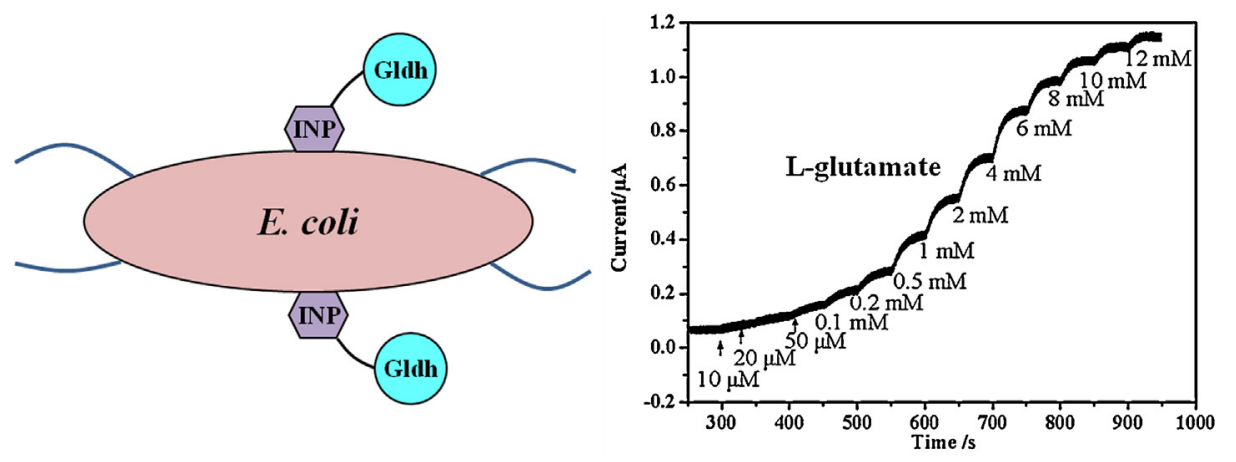

A B S T R A C T

A novel L-glutamate biosensor was fabricated using bacteria surface-displayed glutamate dehydrogenase (Gldh-bacteria). Here the cofactor $\mathrm{NADP}^{+}$-specific dependent Gldh was expressed on the surface of Escherichia coli using $\mathrm{N}$-terminal region of ice nucleation protein (INP) as the anchoring motif. The cell fractionation assay and SDS-PAGE analysis indicated that the majority of INP-Gldh fusion proteins were located on the surface of cells. The biosensor was fabricated by successively casting polyethyleneimine (PEI)-dispersed multi-walled carbon nanotubes (MWNTs), Gldh-bacteria and Nafion onto the glassy carbon electrode (Nafion/Gldh-bacteria/PEI-MWNTs/GCE). The MWNTs could not only significantly lower the oxidation overpotential towards NAPDH, which was the product of $\mathrm{NADP}^{+}$involving in the oxidation of glutamate by Gldh, but also enhanced the current response. Under the optimized experimental conditions, the current-time curve of the Nafion/Gldh-bacteria/PEI-MWNTs/GCE was performed at $+0.52 \mathrm{~V}$ (vs. SCE) by amperometry varying glutamate concentration. The current response was linear with glutamate concentration in two ranges $(10 \mu \mathrm{M}-1 \mathrm{mM}$ and $2-10 \mathrm{mM}$ ). The low limit of detection was estimated to be $2 \mu \mathrm{M}$ glutamate $(\mathrm{S} / \mathrm{N}=3)$. Moreover, the proposed biosensor is stable, specific, reproducible and simple, which can be applied to real samples detection.

(c) 2015 Elsevier B.V. All rights reserved.

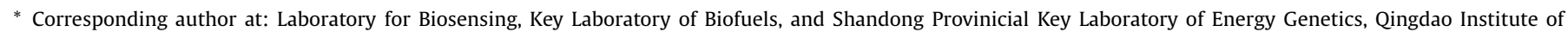
Bioenergy \& Bioprocess Technology, Chinese Academy of Sciences, 189 Songling Road, Qingdao, 266101, China. Tel.: +86 53280662758 ; fax: +86 532 80662778.

E-mail address: liuah@qibebt.ac.cn (A. Liu).

1 These authors contributed equally to this work.
} 


\section{Introduction}

L-Glutamate plays important roles in many fields including bioprocess monitoring [1,2], biomedical application [3,4] and food processing [5]. As a functional amino acid, it is a crucial excitatory neurotransmitter in the central nervous system. For most eukaryon and mammalian, L-glutamate can serve as energy and nitrogen source [6-8]. In addition, L-glutamate has been widely used as the flavor enhancer in foodstuffs such as monosodium glutamate (MSG), chicken essence, soy sauce and some snack seasonings. However, excess amount of L-glutamate in vivo might cause neurological disease such as stroke, Parkinson's disease $[9,10]$, as well as some allergic effects like headache and stomachache $[11,12]$. Furthermore, it is related to the term "Chinese restaurant syndrome" caused by ingestion of food in rich of MSG [13-17]. Therefore, the issue on MSG safety was attracted around the world. The Joint Food and Agriculture Organization of the United Nations/ World Health Organization (FAO/WHO) Expert Committee on Food Additives suggested that MSG was safe on the condition that the doses were not higher than $30 \mathrm{mg} \mathrm{kg}^{-1}$ body weight [18]. The Chinese Center for Disease Control and Prevention Institute of Nutrition and Food Safety concluded that consumption of MSG for adults in China had a certain relationship with overweight. Similar results were reported by researchers at the University of North Carolina [19]. So it is very necessary to develop a rapid and sensitive method to detect L-glutamate in biological and food samples. So far, much efforts have been devoted to develop detection methods of L-glutamate, such as high performance liquid chromatography (HPLC) [20], capillary electrophoresis [21,22], optical methods [23-25] and electrochemical analyses [26,27]. Among these approaches, electrochemical methods, especially electrochemical biosensors, have attracted much attention due to their high sensitivity, rapid response and easy operation [28-31]. However, some electrochemical biosensors had poor selectivity $[32,33]$. Glutamate oxidase (GLOx) and glutamate dehydrogenase (Gldh) were most common enzymes used in the preparation of L-glutamate biosensors. The GLOx based L-glutamate biosensors needs high overpotential and was easily effected by interferents owing to the detection of generated $\mathrm{H}_{2} \mathrm{O}_{2}$ [34-37]. Gldh has been used for the construction of electrochemical glutamate biosensors [38-41], nevertheless, these sensors experienced either complicated in fabrication, or stability or sensitivity issue, which is probably ascribed to Gldh in part.

Many studies showed that enzyme could be displayed on the cell surface of bacteria and retain its relative spatial structure and biological activity $[42,43]$. Gldh is widely existed in various living organisms and involved in amino acid metabolism [44]. Heterologous expression of Gldh from the terrestrial hyperthermophilic archaeon Thermococcus waiotapuensis has been reported [45]. The purified Gldh showed excellent enzyme activity and good thermal stability. However, the purification of the native or recombinant enzyme was time-consuming and gave very low yield. The bacterial cell surface display provides an effective way to overcome this disadvantage by exposing the target enzyme to the exterior of biomembrane with good activity and stability [46-49]. For the first time, we had successfully realized the cell surface displaying of Gldh from T. waiotapuensis using INP as an anchoring motif. The cultured bacterial surface displaying Gldh (Gldh-bacteria) exhibited superior Gldh activity, thermostability and selectivity [50]. Further, it was proved to be $\mathrm{NADP}^{+}$(nicotinamide adenine dinucleotide phosphate) specific dependency, that is, the Gldhbacteria can be involved in reaction 1 to generate NADPH. Thus, the Gldh-bacteria could become the promising candidate for biosensing of L-glutamate, which is based on the measurement of enzymatically generated NADPH (the reduced form of nicotinamide adenine dinucleotide phosphate). glutamate $+\mathrm{NADP}^{+}+\mathrm{H}_{2} \mathrm{O} \stackrel{\text { Gldh2 }}{\longrightarrow}-$ oxoglutarate $+\mathrm{NADPH}$

$$
+\mathrm{NH}_{3}+\mathrm{H}^{+}
$$

In the present work, a L-glutamate biosensor was fabricated by modifying Gldh-bacteria and multiwalled carbon nanotubes (MWNTs) onto a glassy carbon electrode (GCE). The proposed amperometric sensor can detect L-glutamate at $0.52 \mathrm{~V}$ (vs. SCE) with good selectivity and stability. Additionally, other amino acids and common electroactive compounds such as ascorbic acid (AA) and uric acid (UA) have no interference on the detection of glutamate. The as-prepared L-glutamate sensor was capable of real sample measurements.

\section{Materials and methods}

\subsection{Chemicals and reagents}

AA, UA and polyethyleneimine (PEI, molecular weight: 80,000) were bought from Sinopharm Chemical Reagent Co., Ltd. (Shanghai, China). NADP ${ }^{+}$and NADPH were purchased from Bio Basic Canada Inc. Nafion (perfluorinated ion-exchange resin, $5 \mathrm{wt} \%$ solution in a mixture of lower aliphatic alcohols and water) was purchased from Aldrich (St. Louis, MO, USA), from which $0.05 \mathrm{wt} \%$ Nafion solution was prepared. Amino acids including L-glutamate (Glu), L-lysine (Lys), L-threonine (Thr), L-serine (Ser), L-argininie monohydrochloride (Arg), L-methionone (Met), L-valine (Val), L-histidine (His), L-aspartic acid (Asp), L-phenylalanine (Phe) and L-leucine (Leu) were purchased from Blue Quarter Science and Technology Development Co., Ltd. (Shanghai, China). MWNTs were purchased from Shenzhen Nanometer Port Co., Ltd. (Shenzhen, China). Ultrapure water was prepared using a Milli-Q system (Millipore, Billerica, MA, USA). Phosphate buffered saline (PBS, $\mathrm{pH}$ 7.4) was used as the supporting electrolyte. All other reagents were of the highest grade and all solutions were prepared with ultrapure water.

\subsection{Apparatus and methods}

All electrochemical experiments were carried out on a CHI660D electrochemical workstation (CH Instruments, Chenhua, Shanghai, China) in a conventional three-electrode system using a modified glassy carbon electrode (GCE, inner diameter of $3 \mathrm{~mm}$ ) as working electrode, a Pt wire as counter electrode and a saturated calomel electrode (SCE) as reference electrode. All potentials in this paper were reported vs. SCE. All electrochemical measurements were performed at room temperature $\left(\sim 25^{\circ} \mathrm{C}\right)$. Amperometric detection was carried out by continuous addition of L-glutamate into the stirring PBS solution ( $\mathrm{pH} 7.4)$ under the applied potential. The effect of dilution on the final concentration has been taken into consideration.

\subsection{Preparation of Gldh-bacteria}

The details for the construction of plasmid pTInaPb-N-Gldh and the production of cell-displayed Gldh have been described in our recent work [50]. Briefly, E. coli strain BL21 (DE3) harboring plasmid pTInaPb-N-Gldh was grown to an $\mathrm{OD}_{600}$ within 0.4-0.6 in LB media with $50 \mathrm{mg} \mathrm{L}^{-1}$ kanamycin at $37^{\circ} \mathrm{C}$, then the expression of INP-Gldh fusion protein was induced with isopropyl- $\beta$-Dthiogalactopyranoside (IPTG) at a final concentration of $0.4 \mathrm{mM}$ at $25^{\circ} \mathrm{C}$ overnight. Gldh displayed cells were harvested and resuspended in $100 \mathrm{mM}$ Tris- $\mathrm{HCl}$ buffer ( $\mathrm{pH}$ 8.0). The cell fractionation and enzyme activity assay were conducted according to our previous study. 


\subsection{Preparation of PEI-MWNTs dispersion}

Briefly, the PEI-MWNTs dispersion was obtained by dispersing $1 \mathrm{mg}$ of MWNTs into $1 \mathrm{~mL}$ of $1 \mathrm{mg} \mathrm{mL}^{-1}$ PEI aqueous solution under ultra-sonication for at least $30 \mathrm{~min}$.

\subsection{Preparation of modified electrodes}

GCEs were sequentially polished on polishing pad with slurries of $0.5,0.1$ and $0.05 \mu \mathrm{m}$ alumina particles, and carefully cleaned by ultra-sonication in ethanol and water during each step. Then, $5 \mu \mathrm{L}$ of the PEI-MWNTs dispersion was carefully dropped onto the inverted GCE, and let to dry at room temperature, followed by $5 \mu \mathrm{L}$ of $0.05 \%$ Nafion was syringed onto the inverted electrode, thus Nafion/PEI-MWNTs/GCE was fabricated. For the construction of Nafion/Gldh-bacteria/PEI-MWNTs/GCE, $5 \mu \mathrm{L}$ Gldh-bacteria was dropped onto the PEI-MWNTs membrane covered electrode, with further drying under ambient condition. Finally, $5 \mu \mathrm{L}$ of $0.05 \%$ Nafion was syringed onto the inverted electrode. Before use, the modified electrodes were washed repeatedly with Milli-Q water to remove the loosely combined modifiers. The Nafion/GCE was prepared for comparison.

\section{Results and discussion}

\subsection{Cell surface display of Gldh}

Gldh encoding gene has been fused into the expression plasmid of INP cell surface display system in our previous study. After induction with IPTG, the expressed Gldh was targeted onto the surface of $E$. coli through INP-mediated display system. The growth condition for Gldh-displayed bacteria has been optimized [50]. To evaluate the expression and transportation of INP-Gldh fusion proteins, the cell fractionation assay and SDS-PAGE analysis were conducted. As shown in Fig. 1, the clear target band could be found in the whole cell and outer membrane fraction, which revealed that the majority of INP-Gldh fusion proteins were located on the surface of cells. Gldh originated from T. waiotapuensis is hexamer of subunits with a molecular weight of ca. $260 \mathrm{kDa}$. The Gldh on the cell surface will also be expressed as hexamer. However, during

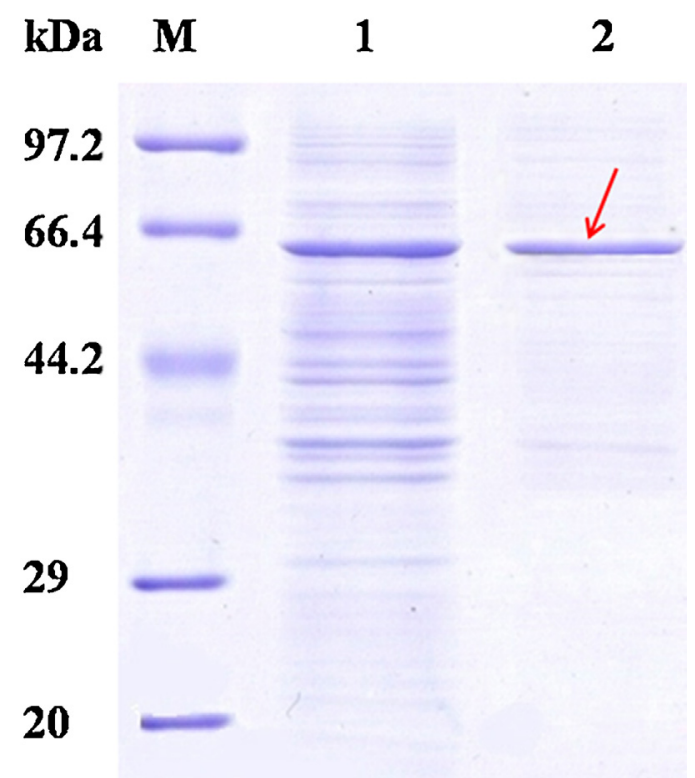

Fig. 1. Analysis of INP-Gldh fusion protein by SDS-PAGE. Lane M, protein standard markers; lane 1, entire cell; lane 2 , outer membrane fraction.
SDS-PAGE analysis, SDS, as ionic detergent, might lead to denaturation of recombinant proteinto form monomer $(60 \mathrm{kDa})$. The entire cell had a favorable Gldh activity of $3.12 \pm 0.12 \mathrm{U} / \mathrm{OD}_{600}$. Our early thermostability test indicated that the enzymatic activity of bacterial displayed Gldh almost remained unchanged over a month at $4{ }^{\circ} \mathrm{C}$. Furthermore, the displayed-Gldh exhibited better specificity than Gldhs from other microbial species reported before [50].

\subsection{Electrocatalytic oxidation of NADPH by Nafion/PEI-MWNTs/GCE}

For cofactor $\left(\mathrm{NAD}^{+}\right.$or $\left.\mathrm{NADP}^{+}\right)$-dependent dehydrogenase based sensor, the enzymatically generated $\mathrm{NAD}(\mathrm{P}) \mathrm{H}$ is usually detected. However, NAD $(P) H$ is reported exhibited high overpotential at bare electrode [51], which means the direct electrochemical detection of $\mathrm{NAD}(\mathrm{P}) \mathrm{H}$ will occur at high potential, arising possible interference from other easily oxidizable species. Therefore, it is important to lower the overpotential of $\mathrm{NAD}(\mathrm{P}) \mathrm{H}$ during electrochemical masurement. The cyclic voltammograms (CVs) of Nafion/PEIMWNTs/GCE and Nafion/GCE in the absence and presence of NADPH were performed. There were no redox peaks in bare PBS solution for the two kinds of modified electrodes (Fig. 2, curves a and b). However, in $1 \mathrm{mM}$ NADPH solution, a broad oxidation peak at about $0.78 \mathrm{~V}$ appeared at Nafion/GCE (Fig. 2, curve c), suggesting the direct oxidation of NADPH. In contrast, a sharp peak with enhanced current was observed at $0.45 \mathrm{~V}$ at Nafion/PEI-MWNTs/ GCE in $1 \mathrm{mM}$ NADPH (Fig. 2, curve d), which was $0.33 \mathrm{~V}$ negative shift in comparison with that value at Nafion/GCE. Moreover, the oxidation peak current at the Nafion/PEI-MWNTs/GCE increased when $2 \mathrm{mM}$ NAPDH was present (Fig. 2, curve e), indicating that the Nafion/PEI-MWNTs/GCE had better electrocatalytic activity to NADPH oxidation, which might be resulted from the excellent catalytic properties of the MWNTs. Similar results were reported for electrocatalytic oxidation of NADH (the reduced form of nicotinamide adenine dinucleotide) at MWNTs modified electrodes [51,52].

\subsection{Electrochemical behavior of Nafion/Gldh-bacteria/PEI-MWNTs/ GCE}

Based on Reaction (1), glutamate can be oxidised to 2-oxoglutarate by Gldh in the aid of cofactor of $\mathrm{NADP}^{+}$, which is then reduced to NADPH. The amount of resultant NADPH is

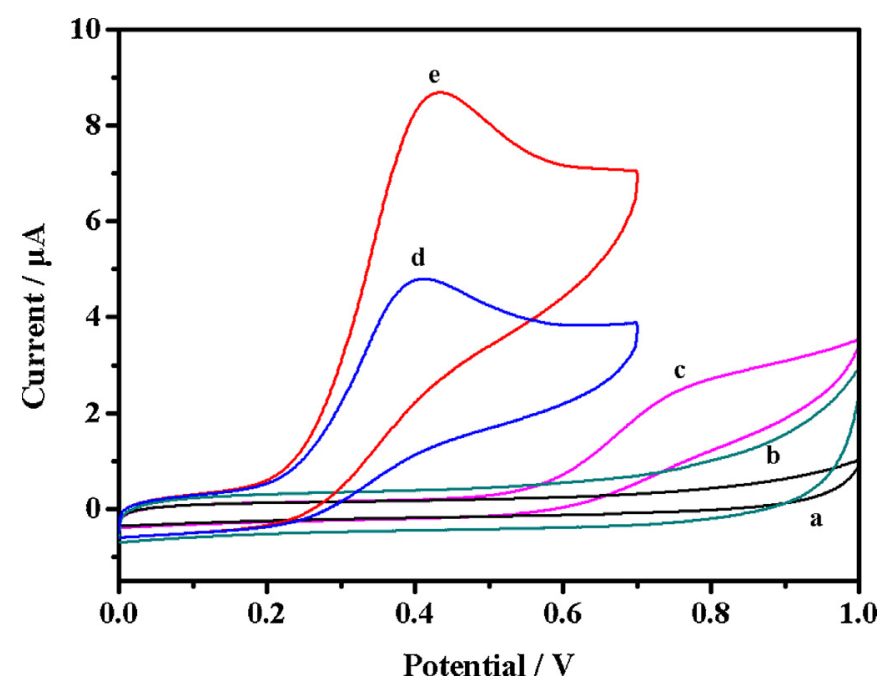

Fig. 2. CVs of Nafion/GCE (a), Nafion/PEI-MWNTs/GCE (b) in bare PBS buffer, and Nafion/GCE in $1 \mathrm{mM}$ NADPH (c), Nafion/PEI-MWNTs/GCE in $1 \mathrm{mM}$ (d) and $2 \mathrm{mM}$ NADPH (e) buffered with $0.1 \mathrm{M}$ PBS ( $\mathrm{pH} 7.4$ ). Scan rate, $50 \mathrm{mV} \mathrm{s}^{-1}$. 
proportional to L-glutamate concentration. To investigate the electrocatalytic activity of different modified electrode to L-glutamate oxidation, CVs of various modified electrodes were measured in $0.1 \mathrm{M}$ PBS ( $\mathrm{pH} 7.4$ ) containing $1 \mathrm{mM} \mathrm{NADP}^{+}$in the absence or in the presence of L-glutamate. Nafion/PEI-MWNTs/GCE did not show any oxidition peaks in $0.1 \mathrm{M}$ PBS ( $\mathrm{pH}$ 7.4) containing $1 \mathrm{mM} \mathrm{NADP}{ }^{+}$and L-glutamate within the potential window of $0-0.8 \mathrm{~V}$ (data not shown). For the Nafion/Gldh-bacteria/PEIMWNTs/GCE, there were no observable redox peaks in solution containing $1 \mathrm{mM} \mathrm{NADP}^{+}$in the absence of L-glutamate (Fig. 3, curve a), while a sharp oxidation peak appeared at about $0.54 \mathrm{~V}$ after addition of $1 \mathrm{mM}$ L-glutamate, which could be resulted from the oxidation of the resultant NADPH at MWNTs (Fig. 3, curve b). Further, with the increase of L-glutamate concentration from 1 to $10 \mathrm{mM}$ (Fig. 3, curves b-d), the oxidation peak current at $0.54 \mathrm{~V}$ enhanced, confirming that the electrocatalytic oxidation of L-glutamate occurred on the Nafion/Gldh-bacteria/PEI-MWNTs/ GCE.

\subsection{Amperometric detection of L-glutamate}

The typical current-time response was carried out at an applied potential of $0.52 \mathrm{~V}$ by amperometry using Nafion/Gldh-bacteria/ PEI-MWNTs/GCE in the stirring PBS (pH 7.4) containing $1 \mathrm{mM}$ $\mathrm{NADP}^{+}$upon successive addition of glutamate. As shown in Fig. 4A, the oxidation current increased upon successive injection of L-glutamate from $10 \mu \mathrm{M}$ to $12 \mathrm{mM}$. The current response was linear with L-glutamate concentration in two ranges: one was ranging from $10 \mu \mathrm{M}$ to $1 \mathrm{mM}$ with the linear regression equation of $y=0.037+0.310 x(R=0.996)$ (Fig. 4B). Another linear range was within $2-10 \mathrm{mM}$ with the linear regression equation of $y=0.400+0.067 x(R=0.995)$ (Fig. 4B). The lower limit of detection (LOD) was estimated to be about $2 \mu \mathrm{M}(\mathrm{S} / \mathrm{N}=3)$. In this respect, various methods have been reported with typical linear ranges and LODs (Table 1). Obviously, the Nafion/Gldh-bacteria/PEI-MWNTs/ GCE showed wider dynamic detection ranges and corresponding lower detection limit, in comparison with most purified Gldh based sensors reported so far $[40,41,53,54]$. The Gldh-bacteria in present work exhibited high activity, specificity and stability, which could be used directly without further labored enzyme extraction and purification, thus greatly improved the stability of the enzyme and sensitivity of the sensor.

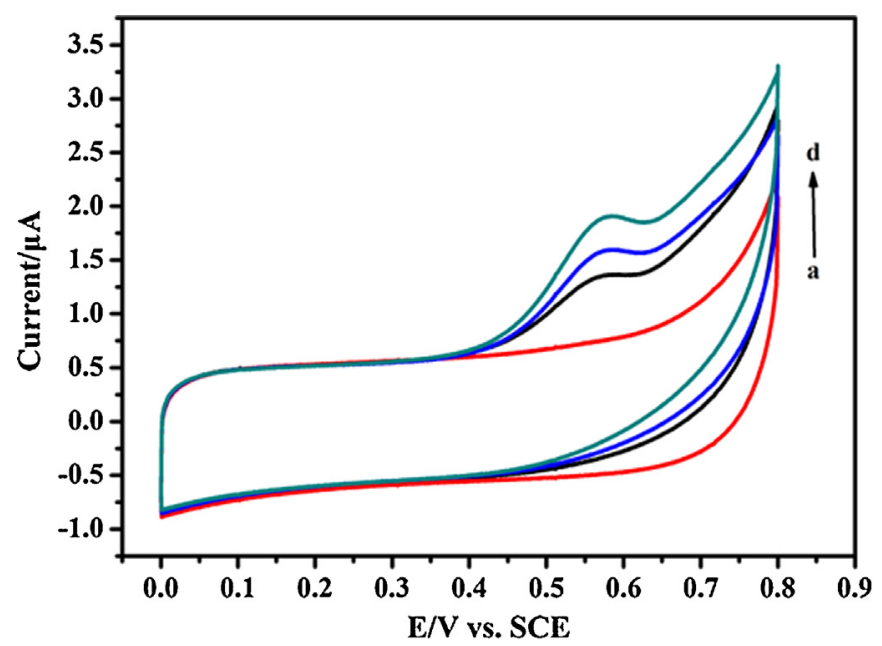

Fig. 3. CV curves of Nafion/Gldh-bacteria/PEI-MWNTs/GCE in the presence of $1 \mathrm{mM}$ $\mathrm{NADP}^{+}$with 0 (a), 1 (b), 5 (c) and $10 \mathrm{mM}$ L-glutamate (d) buffered with $0.1 \mathrm{M}$ PBS (pH 7.4). Scan rate: $50 \mathrm{mV} \mathrm{s}^{-1}$.
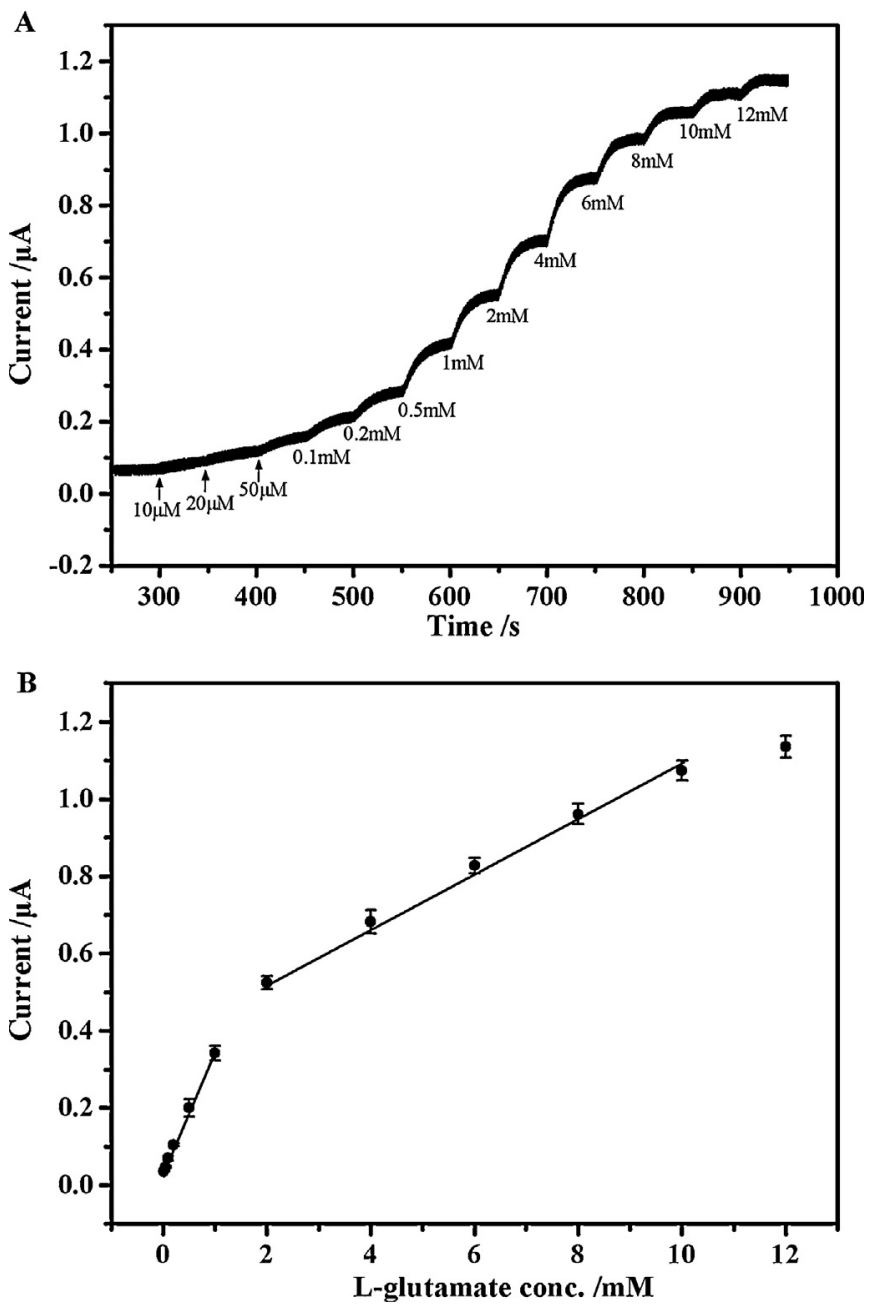

Fig. 4. (A) Current-time curve of Nafion/Gldh-bacteria/PEI-MWNTs/GCE with successively addition of L-glutamate into $0.1 \mathrm{M}$ PBS ( $\mathrm{pH} 7.4$ ) containing $1 \mathrm{mM}$ $\mathrm{NADP}^{+}$. Applied potential: $0.52 \mathrm{~V}$. (B) Typical calibration graph of the biosensor for L-glutamate.

Table 1

Analytical performance of different methods for L-glutamate detection.

\begin{tabular}{|c|c|c|c|}
\hline Method & $\begin{array}{l}\text { Linear range } \\
(\mu \mathrm{M})\end{array}$ & $\begin{array}{l}\text { LOD } \\
(\mu \mathrm{M})\end{array}$ & Refs. \\
\hline HPLC & $10-200$ & $\mathrm{NA}^{\mathrm{a}}$ & {$[20]$} \\
\hline $\begin{array}{l}\mathrm{Cu}^{2+} \text {-polyamine cage involved fluorescence } \\
\text { detection }\end{array}$ & $5-20$ & $\mathrm{NA}^{\mathrm{a}}$ & [55] \\
\hline GLOx/oxygen electrode & $68-1360$ & 68 & {$[56]$} \\
\hline Nafion/methyl viologen/GCE & $20-750$ & 20 & [38] \\
\hline $\begin{array}{l}\text { Poly }(o \text {-phenylenediamine }) / \text { Gldh/carbon } \\
\text { paste electrode }\end{array}$ & $5-78$ & 3.8 & {$[40]$} \\
\hline Ceria/titania nanoparticles/GLOx & $5-90$ & 0.59 & {$[34]$} \\
\hline Gldh/diaphorase nanocomposite electrode & $10-3495$ & 5.4 & [53] \\
\hline Gldh/chitosan/GCE & $5-500$ & 5 & [39] \\
\hline $\begin{array}{l}\text { Phenothiazine/methylene green/Gldh/ } \\
\text { carbon paste electrode }\end{array}$ & $50-10,000$ & 5 & {$[41]$} \\
\hline Gldh/TiO ${ }_{2}$ sol-gel optical biosensor & $40-10,000$ & 5.5 & {$[54]$} \\
\hline Optical array-based $\mathrm{TiO}_{2}$ biosensor & $10-10,000$ & 2.4 & [25] \\
\hline Gldh-bacteria based optical detection & $10-400$ & 6 & [50] \\
\hline Nafion/Gldh-bacteria & $10-1000$ & 2 & $\begin{array}{l}\text { Current } \\
\text { work }\end{array}$ \\
\hline /PEI-MWNTs/GCE & $2000-10,000$ & & \\
\hline
\end{tabular}

a NA: not available. 


\subsection{Selectivity of the sensor}

To study the selectivity of the sensor, the current responses after successive addition of $0.5 \mathrm{mM}$ L-glutamate and $10 \mathrm{mM}$ other species by amperometry at $0.52 \mathrm{~V}$. The addition of other amino acids including Lys, Thr, Ser, Arg, Met, Val, His, Asp, Phe and Leu (each $10 \mathrm{mM}$ ) exhibited no current change (Fig. 5, arrows b-k), indicating the specificity of the Gldh-bacteria [50]. On the other hand, the addition of AA and UA (each $10 \mathrm{mM}$ ) did not generate the current signal (Fig. 5, arrows 1 and $\mathrm{m}$ ), suggesting that excess of these common interfering species had no interference to the detection of $0.5 \mathrm{mM}$ glutamate (Fig. 5, arrow a), probably orginating from that both UA and AA are negatively charged in PBS buffer ( $\mathrm{pH}$ 7.4), exerting electrostatic repulsion with the negatively charged Nafion film. Finally, the current response was increased accordingly upon addition of $0.3 \mathrm{mM}$ glutamate (Fig. 5, arrow $\mathrm{n}$ ). Taken together, the sensor exhibited a good selectivity to glutamate.

\subsection{Stability of the sensor}

To investigate the operational stability of the sensor, the amperometric response of Nafion/Gldh-bacteria/PEI-MWNTs/GCE to $1 \mathrm{mM}$ L-glutamate was examined at an applied potential of $0.52 \mathrm{~V}$ over a period of more than $2 \mathrm{~h}$ (Fig. 6). The oxidation current still remained about $95 \%$ of the initial response after two hours recording, suggesting the good operational stability of the sensor.

The long-term stability of the biosensor was also investigated in $1 \mathrm{mM}$-glutamate in $0.1 \mathrm{M}$ PBS ( $\mathrm{pH} 7.4$ ) containing $1 \mathrm{mM} \mathrm{NADP}^{+}$. The current response was measured every day and the modified electrode was stored in $4{ }^{\circ} \mathrm{C}$ fridge when it was not in use. The current response reduced slightly, however, $93 \%$ of the original value remained after 15-day measurement (Fig. 7), suggesting the favorable long-time stability of the sensor.

\subsection{Analysis of real samples}

The fabricated Nafion/Gldh-bacteria/PEI-MWNTs/GCE was further used to detect L-glutamate in real samples. Before measurements, solid samples were dissolved in water and then filtered through a $0.22 \mu \mathrm{m}$ membrane; after that the filtrates were collected and accurately diluted with PBS buffer to fit into the

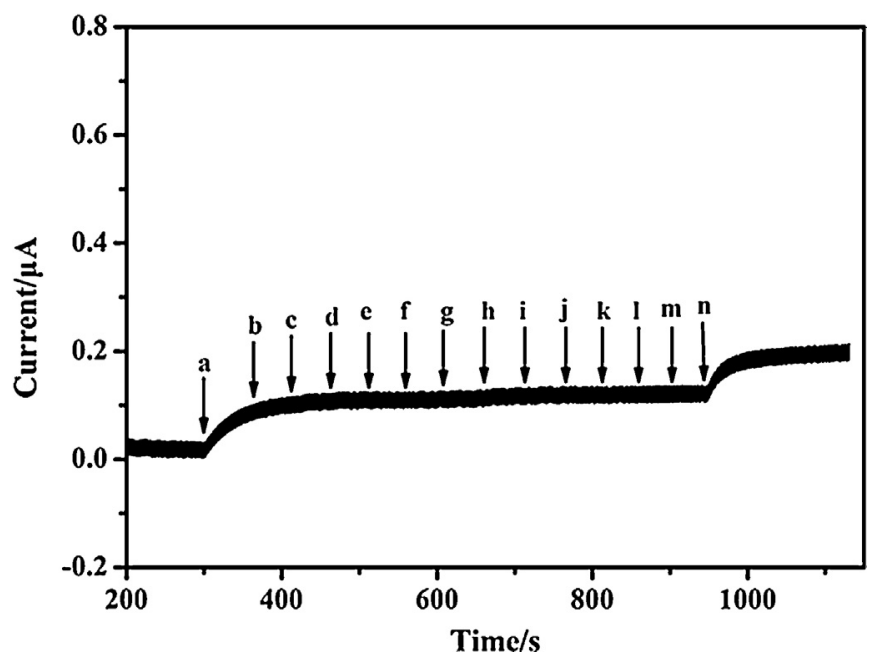

Fig. 5. Amperometric response of Nafion/Gldh-bacteria/PEI-MWNTs/GCE with successive addition of $0.5 \mathrm{mM}$ L-glutamate (arrow a), $10 \mathrm{mM}$ interferents (arrows: b, Lys; c, Thr; d, Ser; e, Arg; f, Met; g, Val; h, His; I, Asp; j, Phe; k, Leu; l, AA; m, UA) and finally $0.3 \mathrm{mM}$ L-glutamate (arrow $\mathrm{n}$ ) into $0.1 \mathrm{M}$ PBS ( $\mathrm{pH} 7.4$ ) containing $1 \mathrm{mM}$ $\mathrm{NADP}^{+}$. Applied potential: $0.52 \mathrm{~V}$

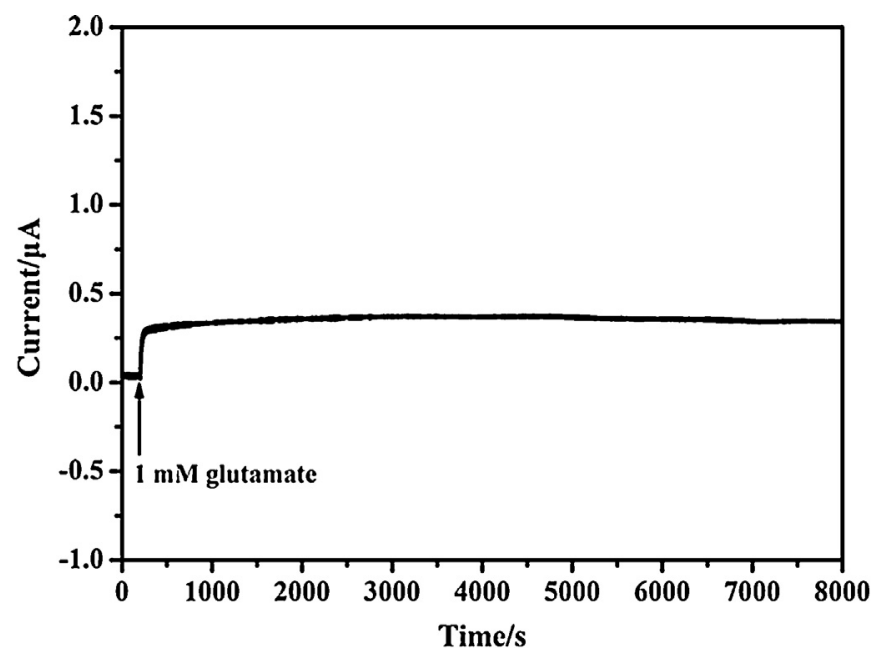

Fig. 6. Amperometric response of Nafion/Gldh-bacteria/PEI-MWNTs/GCE after addition of $1 \mathrm{mM}$ L-glutamate into the stirring $0.1 \mathrm{M} \mathrm{PBS}(\mathrm{pH} 7.4$ ) containing $1 \mathrm{mM}$ $\mathrm{NADP}^{+}$. Applied potential: $0.52 \mathrm{~V}$.

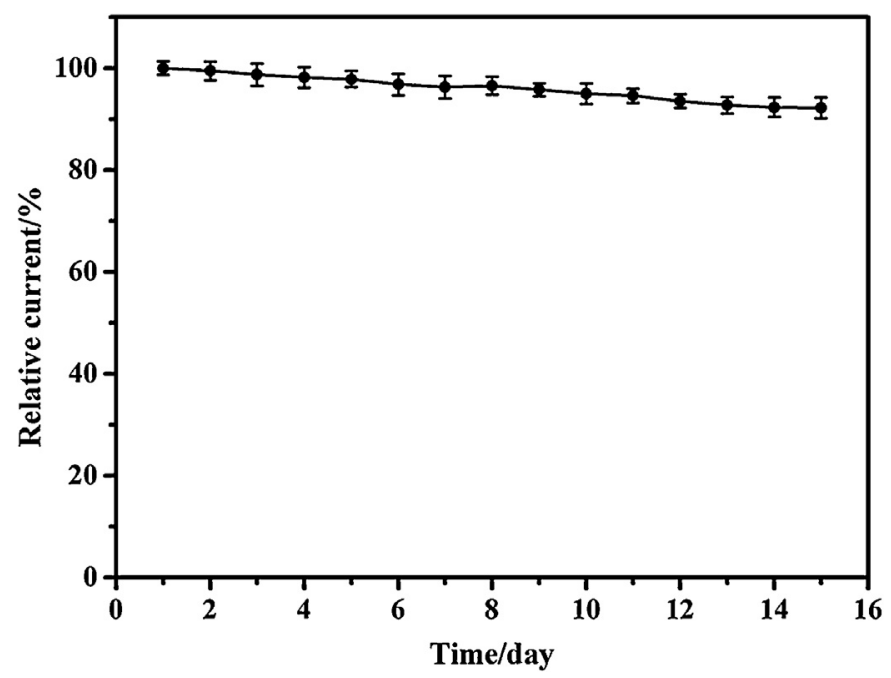

Fig. 7. Storage stability of the biosensor.

linear range of the sensor. Three repetitive detections were performed for each sample. The glutamate contents of real samples were calculated based on the calibration graph multiplying the dilution ratios and shown in Table 2 . The relative error values were within $3 \%$ and relative standard deviation for each sample were within $2.5 \%$, demonstrating that the calibration graph was precise and reliable for L-glutamate analysis in real samples.

Table 2

Determination of L-glutamate in real samples.

\begin{tabular}{lccc}
\hline Sample & \multicolumn{2}{l}{ L-Glutamate content $(\mathrm{w} / \mathrm{w}, \%)$} & \multirow{2}{*}{ Relative error $(\%)$} \\
\cline { 2 - 3 } & This work $^{\mathrm{a}}$ & Nutrition info & \\
\hline$\# 1^{\mathrm{b}}$ & $101.7 \pm 2.5$ & 99.0 & +2.7 \\
$\# 2^{\mathrm{c}}$ & $71.2 \pm 1.8$ & 70.0 & +1.7 \\
$\# 3^{\mathrm{d}}$ & $34.2 \pm 0.7$ & 35.0 & -2.3 \\
$\# 4^{\mathrm{e}}$ & $4.89 \pm 0.13$ & 5.0 & -2.2 \\
\hline
\end{tabular}

a All values referred to the mean of three repetitive measurements plus-minus standard deviation.

b \#1 represents the local MSG.

c \#2 represents the salted MSG.

d \#3 represents the chicken essence seasoning.

e \#4 stands for the local soy sauce seasoning. 


\section{Conclusions}

In summary, INP-mediated cell surface displayed Gldh was prepared. The cell fractionation assay and SDS-PAGE analysis confirmed the correct location of INP-Gldh fusion proteins. A sensitive L-glutamate biosensor (Nafion/Gldh-bacteria/PEIMWNTs/GCE) was constructed. The sensor exhibited two linear parts ( $10 \mu \mathrm{M}-1 \mathrm{mM}$ and $2-10 \mathrm{mM}$ ) and low detection limit of $2 \mu \mathrm{M}$ glutamate. Moreover, this proposed electrochemical microbial biosensor exhibited stability and selectivity to common interferents such as AA and UA as well as other amino acids. Moreover, the as-prepared L-glutamate biosensor was capable of real samples detection precisely.

\section{Acknowledgments}

This work was supported by National Natural Science Foundation of China (Nos. 91227116, 31200598, 21275152 and 21475144) and the Qingdao Institute of Bioenergy and Bioprocess Technology Director Innovation Foundation for Young Scientists (Y37203210S).

\section{References}

[1] M.J. Niciu, B. Kelmendi, G. Sanacora, Overview of glutamatergic neurotransmission in the nervous system, Pharmacol. Biochem. Behav. 100 (2012) 656-664.

[2] G. Riedel, B. Platt, J. Micheau, Glutamate receptor function in learning and memory, Behav. Brain Res. 140 (2003) 1-47.

[3] D. Mathews, I. Henter, C. Zarate Jr., Targeting the glutamatergic system to treat major depressive disorder, Drugs 72 (2012) 1313-1333.

[4] C.G. Parsons, W. Danysz, G. Quack, Glutamate in CNS disorders as a target for drug development: an update, Drug News Perspect. 11 (1998) 523-569.

[5] K. Kurihara, Glutamate: from discovery as a food flavor to role as a basic taste (umami), Am. J. Clin. Nutr. 90 (2009) 719S-722S.

[6] O. Niwa, K. Torimitsu, M. Morita, P. Osborne, K. Yamamoto, Concentration of extracellular L-glutamate released from cultured nerve cells measured with a small-volume online sensor, Anal. Chem. 68 (1996) 1865-1870.

[7] F. Fonnum, Glutamate: a neurotransmitter in mammalian brain, J. Neurochem. 42 (1984) 1-11.

[8] B. Rietz, G.G. Guilbault, Fluorimetric assay of serum glutamate oxaloacetate transaminase, glutamate pyruvate transaminase and $\alpha$-hydroxybutyrate dehydrogenàse by solution an, Anal. Chim. Acta 77 (1975) 191-198.

[9] S.J. Martin, P.D. Grimwood, R.G.M. Morris, Synaptic plasticity and memory: an evaluation of the hypothesis, Annu. Rev. Neurosci. 23 (2000) 649-711.

[10] M. Nedergaard, T. Takano, A.J. Hansen, Beyond the role of glutamate as a neurotransmitter, Nat. Rev.: Neurosci. 3 (2002) 748-755.

[11] F. Bellisleb, Effects of monosodium glutamate on human food palatabilitya, Ann. N. Y. Acad. Sci. 855 (1998) 438-441.

[12] J. Prescott, Effects of added glutamate on liking for novel food flavors, Appetite 42 (2004) 143-150.

[13] D.H. Allen, J. Delohery, G. Baker, Monosodium L-glutamate-induced asthma, J. Allergy Clin. Immunol. 80 (1987) 530-537.

[14] L.H. Goldberg, Supraventricular tachyarrhythmia in association with the Chinese restaurant syndrome, Ann. Emerg. Med. 11 (1982) 333.

[15] L. Tarasoff, M.F. Kelly, Monosodium L-glutamate: a double-blind study and review, Food Chem. Toxicol. 31 (1993) 1019-1035.

[16] P. Aas, R. Tansø, F. Fonnum, Stimulation of peripheral cholinergic nerves by glutamate indicates a new peripheral glutamate receptor, Eur. J. Pharmacol. 164 (1989) 93-102.

[17] C.F. Pulce Verdier, F. Testud, B. Nicolas, J. Descotes, The Chinese restaurant syndrome: a reappraisal of monosodium glutamate's causative role, Adverse Drug React. Toxicol. Rev. 11 (1992) 21.

[18] R. Walker, J.R. Lupien, The safety evaluation of monosodium glutamate, J. Nutr. 130 (4S Suppl) (2000) 1049S-1052S.

[19] K. He, L. Zhao, M.L. Daviglus, A.R. Dyer, L. Van Horn, D. Garside, L. Zhu, D. Guo, Y. Wu, B. Zhou, J. Stamler, I.C.R. Group, Association of monosodium glutamate intake with overweight in chinese adults: the intermap study, Obesity 16 (2008) 1875-1880.

[20] G. Clarke, S. O'Mahony, G. Malone, T.G. Dinan, An isocratic high performance liquid chromatography method for the determination of GABA and glutamate in discrete regions of the rodent brain, J. Neurosci. Methods 160 (2007) 223230.

[21] C.A. Vyas, S.M. Rawls, R.B. Raffa, J.G. Shackman, Glutamate and aspartate measurements in individual planaria by rapid capillary electrophoresis, J. Pharmacol. Toxicol. Methods 63 (2011) 119-122.

[22] T.J. O'Shea, P.L. Weber, B.P. Bammel, C.E. Lunte, S.M. Lunte, M.R. Smyth, Monitoring excitatory amino acid release in vivo by microdialysis with capillary electrophoresis-electrochemistry, J. Chromatogr. A 608 (1992) 189195.
[23] J. Cordek, X. Wang, W. Tan, Direct immobilization of glutamate dehydrogenase on optical fiber probes for ultrasensitive glutamate detection, Anal. Chem. 71 (1999) 1529-1533.

[24] L. Hernandez, S. Tucci, N. Guzman, X. Paez, In vivo monitoring of glutamate in the brain by microdialysis and capillary electrophoresis with laser-induced fluorescence detection, J. Chromatogr. A 652 (1993) 393-398.

[25] R.-a. Doong, H.-m. Shih, Array-based titanium dioxide biosensors for ratiometric determination of glucose, glutamate and urea, Biosens. Bioelectron. 25 (2010) 1439-1446.

[26] E. Athanasiou-Malaki, M.A. Koupparis, Kinetic-potentiometric determination of amino acids based on monitoring their reaction with dinitrofluorobenzene using a fluoride-selective electrode, Analyst 112 (1987) 757-761.

[27] O. Frey, T. Holtzman, R.M. McNamara, D.E.H. Theobald, P.D. van der Wal, N.F. de Rooij, J.W. Dalley, M. Koudelka-Hep, Enzyme-based choline and L-glutamate biosensor electrodes on silicon microprobe arrays, Biosens. Bioelectron. 26 (2010) 477-484.

[28] A.A. Karyakin, E.E. Karyakina, L. Gorton, Amperometric biosensor for glutamate using prussian blue-based artificial peroxidase as a transduce for hydrogen peroxide, Anal. Chem. 72 (2000) 1720-1723.

[29] S.T. Girousi, A.A. Pantazaki, A.N. Voulgaropoulos, Mitochondria-based amperometric biosensor for the determination of L-glutamic acid, Electroanalysis 13 (2001) 243-245.

[30] N. Pasco, C. Jeffries, Q. Davies, A.J. Downard, A.D. Roddick-Lanzilotta, L. Gorton, Characterisation of a thermophilic L-glutamate dehydrogenase biosensor for amperometric determination of L-glutamate by flow injection analysis, Biosens. Bioelectron. 14 (1999) 171-178.

[31] S. Varma, Y. Yigzaw, L. Gorton, Prussian blue-glutamate oxidase modified glassy carbon electrode: a sensitive L-glutamate and $\beta-N$-oxalyl- $\alpha, \beta$-diaminopropionic acid ( $\beta$-ODAP) sensor, Anal. Chim. Acta 556 (2006) 319-325.

[32] N.V. Kulagina, L. Shankar, A.C. Michael, Monitoring glutamate and ascorbate in the extracellular space of brain tissue with electrochemical microsensors, Anal. Chem. 71 (1999) 5093-5100.

[33] S. Pan, M.A. Arnold, Selectivity enhancement for glutamate with a Nafion/ glutamate oxidase biosensor, Talanta 43 (1996) 1157-1162.

[34] R.E. Özel, C. Ispas, M. Ganesana, J.C. Leiter, S. Andreescu, Glutamate oxidase biosensor based on mixed ceria and titania nanoparticles for the detection of glutamate in hypoxic environments, Biosens. Bioelectron. 52 (2014) 397-402.

[35] C. Botrè, F. Botrè, M. Galli, G. Lorenti, F. Mazzei, F. Porcelli, Determination of glutamic acid decarboxylase activity and inhibition by an $\mathrm{H}_{2} \mathrm{O}_{2}$-sensing glutamic acid oxidase biosensor, Anal. Biochem. 201 (1992) 227-232.

[36] M. Jamal, J. Xu, K.M. Razeeb, Disposable biosensor based on immobilisation of glutamate oxidase on Pt nanoparticles modified Au nanowire array electrode, Biosens. Bioelectron. 26 (2010) 1420-1424.

[37] A.K. Kwong, B. Gründig, J. Hu, R. Renneberg, Comparative study of hydrogelimmobilized L-glutamate oxidases for a novel thick-film biosensor and its application in food samples, Biotechnol. Lett. 22 (2000) 267-272.

[38] R. Maalouf, H. Chebib, Y. Saïkali, O. Vittori, M. Sigaud, N. Jaffrezic-Renault, Amperometric and impedimetric characterization of a glutamate biosensor based on Nafion ${ }^{\mathbb{R}}$ and a methyl viologen modified glassy carbon electrode, Biosens. Bioelectron. 22 (2007) 2682-2688.

[39] N.E. Azmi, M. Ahmad, J. Abdullah, H. Sidek, L.Y. Heng, N. Karuppiah, Biosensor based on glutamate dehydrogenase immobilized in chitosan for the determination of ammonium in water samples, Anal. Biochem. 388 (2009) $28-32$.

[40] S.L. Alvarez-Crespo, M.J. Lobo-Castañón, A.J. Miranda-Ordieres, P. TuñónBlanco, Amperometric glutamate biosensor based on poly $(0-$ phenylenediamine) film electrogenerated onto modified carbon paste electrodes, Biosens. Bioelectron. 12 (1997) 739-747.

[41] S.P. Gomes, J. Doležalová, A.N. Araújo, C.M.C.M. Couto, M.C.B.S.M. Montenegro, Glutamate sol-gel amperometric biosensor based on co-immobilised NADP ${ }^{+}$ and glutamate dehydrogenase, J. Anal. Chem. 68 (2013) 794-800.

[42] J. Jose, R. Bernhardt, F. Hannemann, Cellular surface display of dimeric Adx and whole cell P450-mediated steroid synthesis on E. coli, J. Biotechnol. 95 (2002) 257-268.

[43] J.A. Francisco, C.F. Earhart, G. Georgiou, Transport and anchoring of betalactamase to the external surface of Escherichia coli, Proc. Natl. Acad. Sci. U. S. A 89 (1992) 2713-2717.

[44] R.C. Hudson, R.M. Daniel, L-Glutamate dehydrogenases-distribution, properties and mechanism, Comp. Biochem. Phys. B 106 (1993) 767-792.

[45] M.K. Lee, J.M. Gonzalez, F.T. Robb, Extremely thermostable glutamate dehydrogenase (GDH) from the freshwater archaeon Thermococcus waiotapuensis: cloning and comparison with two marine hyperthermophilic GDHs, Extremophiles 6 (2002) 151-159.

[46] S.Y. Lee, J.H. Choi, Z. Xu, Microbial cell-surface display, Trends Biotechnol. 21 (2003) 45-52.

[47] B. Liang, L. Li, M. Mascin, A. Liu, Construction of xylose dehydrogenase displayed on the surface of bacteria using ice nucleation protein for sensitive $\mathrm{D}$ xylose detection, Anal. Chem. 84 (2011) 275-282.

[48] L. Jin, X. Gao, L. Wang, Q. Wu, Z. Chen, X. Lin, Electrochemical activation of polyethyleneimine-wrapped carbon nanotubes/in situ formed gold nanoparticles functionalised nanocomposite sensor for high sensitive and selective determination of dopamine, J. Electroanal. Chem. 692 (2013) 1-8.

[49] B. Liang, Q. Lang, X. Tang, A. Liu, Simultaneously improving stability and specificity of cell surface displayed glucose dehydrogenase mutants to construct whole-cell biocatalyst for glucose biosensor application, Bioresour. Technol. 147 (2013) 492-498. 
[50] J. Song, B. Liang, D. Han, X. Tang, Q. Lang, R. Feng, L. Han, A. Liu, Bacterial cellsurface displaying of thermo-tolerant glutamate dehydrogenase and its application in L-glutamate assay, Enzyme Microb. Technol. 70 (2015) 72-78.

[51] A. Liu, T. Watanabe, I. Honma, J. Wang, H. Zhou, Effect of solution $\mathrm{pH}$ and ionic strength on the stability of poly(acrylic acid)-encapsulated multiwalled carbon nanotubes aqueous dispersion and its application for NADH sensor Biosens. Bioelectron. 22 (2006) 694-699.

[52] M. Zhang, A. Smith, W. Gorski, Carbon nanotube-chitosan system for electrochemical sensing based on dehydrogenase enzymes, Anal. Chem. 76 (2004) 5045-5050.

[53] R. Monošík, M. Streďanský, E. Šturdík, A biosensor utilizing L-glutamate dehydrogenase and diaphorase immobilized on nanocomposite electrode for determination of L-glutamate in food samples, Food Anal. Methods 6 (2013) 521-527.

[54] R.-a. Doong, H.-m. Shih, Glutamate optical biosensor based on the immobilization of glutamate dehydrogenase in titanium dioxide sol-gel matrix, Biosens. Bioelectron. 22 (2006) 185-191.

[55] M. Bonizzoni, L. Fabbrizzi, G. Piovani, A. Taglietti, Fluorescent detection of glutamate with a dicopper(II) polyamine cage, Tetrahedron 60 (2004) 1115911162.

[56] A.K. Basu, P. Chattopadhyay, U. Roychudhuri, R. Chakraborty, Development of biosensor based on immobilized L-glutamate oxidase for determination of monosodium glutamate in food, Indian J. Exp. Biol. 44 (2006) 392-398. 